Article

\title{
The Role of Management Control Systems and Top Teams in Implementing Environmental Sustainability Policies
}

\author{
David Naranjo-Gil \\ Departamento de Economía Financiera y Contabilidad, Universidad Pablo de Olavide, \\ Facultad de Ciencias Empresariales, 41013 Sevilla, Spain; dnargil@upo.es; Tel.: +34-954-349-847 \\ Academic Editors: Pauline Deutz and Marc A. Rosen \\ Received: 8 January 2016; Accepted: 6 April 2016; Published: 12 April 2016
}

\begin{abstract}
This paper simultaneously examines how the design of management control systems and top management team composition help organizations to implement environmental sustainability policies successfully. It also analyzes the effect of those policies on both short-term and long-term performance. A questionnaire was sent to every member of top management teams in 231 public hospitals in Spain. It obtained 457 useful responses from TMT members, allowing us to collect data on 81 full top management teams (35.06\%). The partial least squares statistical technique was used to test the causal research model. It was found that the implementation of environmental sustainability policies has a negative effect on short-term organizational performance and a positive effect on long-term performance. The results show that management control systems and top management team diversity have a complementary effect on implementing policies focused on environmental sustainability. A broad design of management control systems helps organizations adopt sustainability policies to achieve long-term performance. It was also found that top management team diversity mitigates the negative effect of adopting environmental sustainability policies on short-term organizational performance.
\end{abstract}

Keywords: implementation of environmental sustainability policies; management control system design; top management team; short-term and long-term performance

\section{Introduction}

Many organizations across various industries are adopting environmental sustainability policies and practices to reduce costs and increase quality [1,2]. This is especially relevant in the public healthcare sector, where the new public management paradigm serves as a common heading of strategic initiatives that many hospitals have taken to deliver greater efficiency and more responsive public services [3,4]. The benefits of sustainability are more important than ever before, as the health care environment has shifted from a volume-based market to a value-based market [4]. Environmental sustainability policies offer significant financial and environmental benefits for hospitals; for example, by purchasing energy-efficient refrigeration facilities, laundry equipment and data centers, hospitals contribute to cutting energy consumption, which reduces utility costs and helps the environment by reducing the amount of natural resources used. Furthermore, by implementing environmental sustainability policies, hospitals not only contribute to a healthier environment but also improve population health by reducing pollution and reducing the use of community resources such as water and energy [4,5]. For example, hospitals are organizations that use a lot of energy (e.g., refrigeration facilities, food services or computer centers), so the adoption of an energy efficiency policy-a major environmental sustainability strategy-can reduce costs and improve efficiency and performance in the long-term [6,7]. However, the implementation of these environmental initiatives often fails 
in the short term, leading to poor performance and wasted resources in many organizations $[7,8]$. The coexistence of performance gain and loss is likely to yield confounding evidence concerning the success of the implementation of environmental sustainability policies $[9,10]$.

The implementation of environmental sustainability practices requires a combination of coordination and decentralization within the organization [7,11], and management control systems that stimulate fluent working relationships between different levels of organizational functions. Management accounting research has tried to identify the managerial factors that facilitate strategy implementation to enhance both short-term and long-term performance [12,13]. It is argued that the availability of a broader set of management information facilitates and encourages managerial debates and interactions on strategic issues, which are necessary conditions for adopting strategic policies successfully $[14,15]$.

Strategy management research argues that the composition of the top management team affects the strategy implementation in firms $[16,17]$. Previous research has focused on the psychological attributes and observable experiences of top managers as a team, since strategic decisions are often made and implemented through dynamic processes where managers interact, consult and debate with each other. Along these lines, Hambrick [17] argued that heterogeneous TMTs, consisting of managers with varying skills and demographic profiles, can explain the differences in strategic choices, innovativeness and performance of the firms $[18,19]$. By combining insights from the strategy management literature and the management accounting literature, the general objective of this paper is to simultaneously analyze how top management teams and management control systems are able to deal with the implementation of environmental sustainability policies, and to handle the conflicting demands of enhancing short-term and long-term performance.

Data were collected from 81 top management teams of 231 Spanish hospitals in a survey-based study. The Spanish government has encouraged hospitals and management teams to reorganize their activities and adopt environmental sustainability practices; therefore, this setting provided a good chance to analyze how top teams manage strategic change [20]. Overall the results showed a complementary moderating effect of top management team diversity and broad design of management control systems on the relationship between environmental sustainability implementation and both short-term and long-term performance.

This paper makes several contributions to management literature. First, we examined the separate impact of top team diversity and the design of management control systems on implementing environmental sustainability policies. Second, this paper analyzed the complementary effect of management control and organizational mechanisms on strategic performance, so we answer recent calls in the strategic management literature for a better understanding of the processes and arrangement through which organizations implement new strategic policies. Third, despite considerable attention to the relationship between environmental sustainability policies and performance, this is the first study, of which the author is aware, that simultaneously examined the effect of the adoption of environmental sustainability policies on both short-term and long-term organizational performance. Finally, the results from this paper also have practical contributions. Authorities responsible for appointing hospital managers should pay increased attention to the diversity of characteristics among members of the top team. Authorities should also encourage the adoption of comprehensive designs of management control systems in hospitals, since they are key aspects to thriving in the health care environment of the present and future.

The remainder of this paper is structured as follows. First, we develop our hypotheses about the relationship between top management team diversity, management control system design, environmental sustainability polices and performance. Next we describe the empirical study and after that present the results. The final section contains a discussion of the findings and the conclusion of the study. 


\section{Hypotheses Development}

Top management teams are considered to have the potential to achieve strategy implementation and make the organizations more effective [21,22]. The adoption of environmental sustainability policies often requires that top management teams redefine goals and functions, which can create a level or uncertainty for subordinates as to priorities on which to focus their attention in the short-term [16,17]. Furthermore, the implementation of environmental sustainability practices often requires adjustments in related parts of the organization, such as marketing, technology or production, causing coordination and interdependence uncertainty that complicates change $[1,8,23]$. The upper-echelon theory argues that the composition of the top management team affects the strategic choices of the organization and the success of those choices [17,24]. Authors following upper echelon tradition have argued that demographic characteristics, such as age, gender, tenure, educational and functional background are indicative of underlying cognitive and affective managerial characteristics that determine the decisions of management teams, which subsequently affect organizational performance [25,26]. Recently upper echelon literature has focused on the heterogeneity of top management teams (TMT), where several authors have shown that heterogeneity provides TMTs with a greater variety of professional perspectives, types of knowledge and decision-making styles $[27,28]$. This should result in more ideas and more creativity in the development of environmental strategic actions. In this regard, several authors have argued that heterogeneous TMTs, consisting of managers with varying skills and demographic profiles, can explain the relationship between strategic policy implementation, control and organizational performance $[25,28,29]$.

The adoption of new environmental sustainability policies and practices puts great demands on organizations and their management teams, resulting in a threat to organizations' short-term performance [30,31]. Diverse TMTs can better deal with the resulting coordination problems, since they have a more comprehensive view of the formal structures and informal networks in the organization $[16,27]$, and thus they can avoid frictions that might prevent the organization from performing optimally in the short-term. A diverse TMT will also have better skills to search for solutions from a variety of sources, as determined by their background and cognitive make-up [28,29]. The diversity of experience and knowledge spurs top managers to gather and process more comprehensive and varied alternatives, which helps them to react promptly to the lack of coordination that causes the adoption of new strategic policies [32,33]. Heterogeneous TMTs are found to be broader-minded and to have a larger portfolio to quickly respond to new demands $[28,33,34]$. Furthermore heterogeneous TMTs are demonstrated to have a richer knowledge about organizational processes, which let them to provide fast service $[16,17,24]$. Thus, in the implementation of strategic policies, a diverse TMT is more likely to react and face problems better in the short term than the long term. Therefore, we formulate the following hypothesis:

H1: TMT diversity moderates the relationship between the implementation of environmental sustainability policies and performance, such that the relationship will be more positive in short-term performance than in long-term performance.

The implementation of environmental sustainability policies typically involves significant breaks from organizational inertia and past routines and includes functional changes as well [9,35]. For example, developing or enhancing an organization's recycling program, implementing a battery recycling program or adopting a "cost, quality, outcomes" approach to purchasing, which considers the purchase price as well as quality for patient care, facility operations and maintenance costs, disposal costs and other factors. Thus, organizations are required to learn new routines, and this situation impose additional demands on the organization's information processing capabilities $[13,36]$. For environmental sustainability implementation to result in improved organizational outcomes, it will be necessary for organizations to adopt broad management control systems. Management control systems can be defined as the formal, information-based routines and procedures managers use to influence and motivate subordinates to perform organizational activities and to achieve strategic goals 
(e.g., balanced scorecard, budget, activity based costing, etc.). These control systems provide top managers with a comprehensive range of management information that facilitates strategy implementation and performance achievement, such as financial and operational information and information about external and internal events [37,38]. In studies on the relationship between management control systems (MCS) and strategy, MCS has been defined in terms of the scope of available information [13,38]. Scope refers to the type and extension of MCS information in time and space. Narrow-scope information is derived from financial information, internal to the organization and with a historic orientation. Alternatively, broad-scope information also includes external, non-financial and future oriented information. Broad-scope MCS information facilitates organizational adaptation, flexibility and performance achievement [38,39].

Environmental sustainability implementation is generally believed to be essential for funding and resource allocation among programs, which is viewed as a critical success factor for the continuance of delivery of services, especially from the nonprofit perspective $[3,11,40]$. The adoption of environmental sustainability policies and practices involves venturing into new routines, whose unpredictability requires broad-scope information and more sophisticated management control systems to succeed $[23,39]$. The availability of a broader set of information encourages managerial debates and interactions on strategic issues and facilitates organizations to achieve long-term goals [36,41]. Accounting mechanisms and structure changes slowly in organizations, and MCS design is likely to change slowly in organizations [13,40]. Thus a broad MCS design is likely to better encourage organizations to adopt environmental sustainability policies to achieve long-term performance over short-term performance. However, Chenhall [36] and Bouwens and Abernethy [38] argued that the availability of a broader set of information gives managers focus for long-term goals and lets them better understand the interdependence of organizational actions in the short term. Thus, we expect that a broad design of management control systems will support organizations in coping with strategic reorientation and help them to be more effective in the long term than in the short term. Therefore, we formulate the following hypothesis:

H2: A broad design of management control system moderates the relationship between the implementation of environmental sustainability policies and performance, such that the relationship will be more positive in long-term performance than in short-term performance.

Figure 1 shows the general research model of this paper.

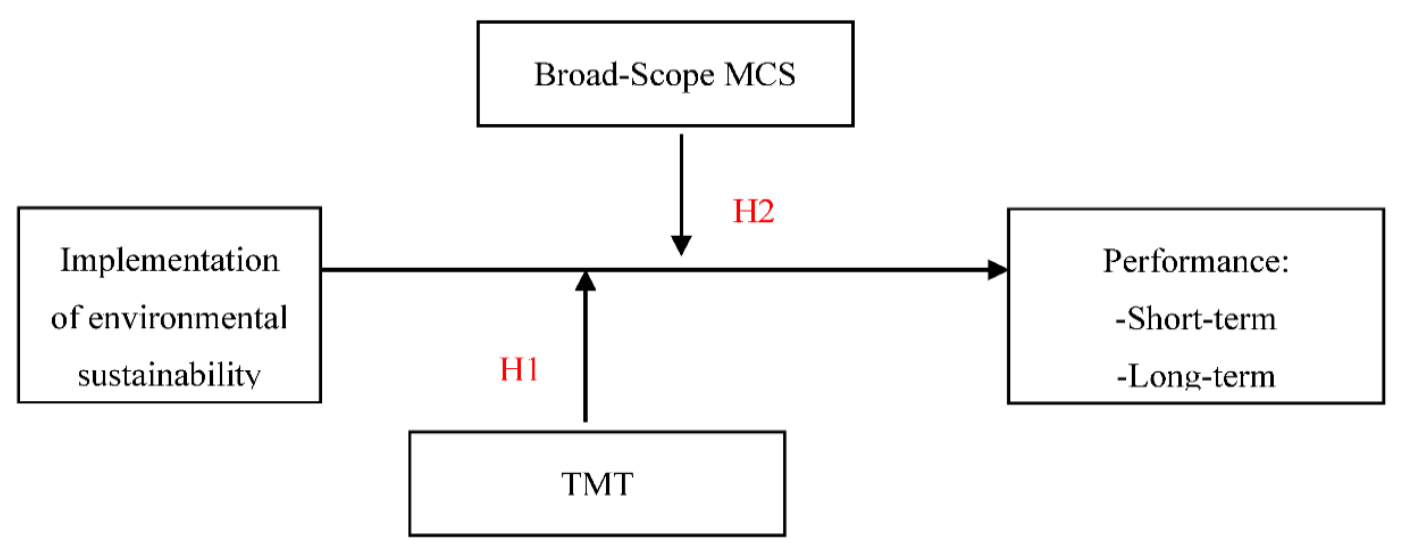

Figure 1. General research model.

\section{Methodology and Measurement}

Our hypotheses were tested using data from the public hospital sector in Spain. Public hospitals, not only in Spain but also in other countries, are forced to undergo fundamental shifts to a more environmental sustainable business model, and to embed sustainability into the core operating model 
of hospitals [11,20]. These reasons assured that the issues central to this study were considered to be relevant for the population. The TMT members' data were obtained from the Spanish National Catalogue of Hospitals. This catalogue contains updated information about the name, position and contact information of top managers in Spanish hospitals, which made it easier to send the questionnaire individually to managers in hospitals' top teams. The dataset that we use contains both survey and archival data. We used a questionnaire survey to collect information on management control systems and the adoption of environmental sustainability policies. Performance was measured using hard data, which we acquire from the annual reports by Spanish health care authorities. The questionnaire was designed and administrated in accordance with the guidelines of Dillman's [42] Tailored Design Method and was sent to top managers of all public hospitals in Spain.

Regarding data collection, a questionnaire was sent to every member of Top Management Teams in the all 231 public hospitals in Spain. We obtained 490 individual responses from TMT members, of which 457 responses appeared to be useful for analysis. From these responses we were able to collect data on 81 complete top management teams $(35.06 \%)$, as the teams for which all members answered the questionnaire. These full teams were used to test our research questions. We compared survey respondents with the original mailing list to test for validity and for potential non-response bias. We also compared the answers provided by early and late respondents. Independent-sample t-tests and Chi-square tests based on the hospital size did not reveal any sign of bias.

\section{Measurement of Variables}

Top management team diversity was measured following the upper echelons tradition [17,24], which focuses on four demography characteristics of TMTs, such as age, tenure, education, experience and gender. Regarding age and tenure, managers were asked to indicate their age and tenure in a management position in their actual organization. Then, age diversity and tenure diversity were measured using the coefficient of variation (standard deviation divided by the mean), which provides a direct and scale-invariant measure of dispersion. Scale invariant measures are desirable because they are sensitive to relative rather than absolute differences. Regarding education and experience, managers were asked to indicate their university degree and their years of functional experience; the responses were coded in two broad areas: External-Administrative Oriented (e.g., Business, Economics, Law) and Internal-Process Oriented (e.g., Medicine, Nursing, Biology and Chemistry). Educational diversity and experience diversity were measured using Blau's index of heterogeneity, since categorical variables are not amenable to the coefficient of variation measure. The Blau's Heterogeneity Index is calculated as $\left(1-\sum\right.$ pi2), where pi is the proportion of the team in the ith educational (or functional) category. A score of zero would indicate perfect managerial homogeneity (functional or educational). Higher scores on this index would indicate higher diversity in functional background between members of the TMT. We also use the Blau index to measure gender diversity in the team, where a score of zero would indicate a TMT of male managers, and higher scores on this index would indicate higher gender diversity in the TMT.

We measured TMT diversity as a construct formed by the following five variables: age, tenure, education, experience and gender diversity. The reliability and validity analyses showed that all items were loading higher in this construct. Since members in the TMT have different characteristics, we calculated an inter-rater reliability coefficient for testing the appropriateness of aggregation of individual characteristics to a team level. All coefficients computed were above 0.70 , which indicates good agreement among judgments made by the team members.

Broad-scope management control systems was measured with a five point Likert scale that addressed the perceived usefulness of several aspects of the available MCS information [36,38], slightly adapted to the hospital setting. This scale acknowledges the difference between management control information that is perceived as useful and management control information that is actually available. The questions regard four informational scope dimensions, which are non-financial oriented, future oriented, external orientation, and long-term oriented. This type of management control information is available in 
Spanish public hospitals through a system known as INIHOS (Information Inter Hospitals), which provides indicators used for measuring, comparing and evaluating health care performance among hospitals. All items regarding the four scope dimensions were loaded higher in the broad-scope construct. Furthermore, Cronbach alpha and composite reliability were also satisfactory, exceeding the recommended levels with 0.803 and 0.846 , respectively.

The implementation of strategic policies related to environmental sustainability was measured with a Likert-type instrument based on strategic management literature [13,35]. The instrument was adapted to the context, by assuring that the selected items were explicitly stated in the governmental policy documents about environmental sustainability strategies. Respondents were asked to indicate the extent to which these sets of strategic policies were implemented in their hospital, such as energy-efficient policies; policies to reduce wasteful or unnecessary water consumption; policies to reduce regulated medical waste generation; policies to develop or enhancing an organization's recycling program; and policies to examine equipment and building systems to determine whether they are operating as designed. The exploratory factor analysis revealed one factor, explaining $35.76 \%$, and Cronbach alphas of 0.78 .

Short-term and long-term performances were measured using performance hard data from Spanish Hospitals, which are published by the Health Care Regional Services. We used data for six nonfinancial performance indicators from 2008 to 2014, which indicated the efficiency of the use of health resources in the key hospital areas, such as hospitalization, surgery, and outpatient service $[20,43]$. These six indicators were: occupancy rate, use of surgery rooms, re-admission rate, length of stay, mortality rate, and waiting time. Short-term performance was measured with data from 2011, the following year after the survey was conducted, and long-term performance was measured with data of the whole period. Performance was also measured by using different combinations of the six indicators. We grouped them in the key hospital areas (hospitalization, surgery and outpatient). We also used other combinations of these six indicators regarding the considered time periods. The results are basically unchanged and demonstrate robustness across various operationalization of performance.

Hospital size and care complexity were used as control variables. Hospital size was measured as the number of beds. Care complexity was measured using data on the hospitals' Case-Mix Index [44]. This index indicated the care complexity according to the average diagnosis-related group weight. A score higher than 1 indicates a hospital's case mix is more complex than the standard case mix [44].

\section{Results}

We used Partial Least Squares technique (PLS) for testing our hypotheses. PLS is a second generation statistical technique for the estimation of path models involving latent constructs indirectly measured by several indicators. Different from covariance-based structural models (e.g., LISREL, EQS), PLS explains variance and resembles ordinary least squares regression, with regard to output and assumptions [45]. As such, PLS allows smaller simple sizes than covariance-based models. PLS also no make assumptions about how variables are distributed, which provides the flexibility and freedom to use any kind of indicator variables. PLS does not report on the fit of the whole model [46], and thus overcomes some of the theoretical and estimation problems associated with the use of covariance-based models.

Table 1 shows the descriptive statistics, where gender diversity is relatively low. Most top managers in Spanish hospitals are male, and only $18.42 \%$ of managers are women. In this respect, during the last decade, women have gradually increased their participation in hospitals' management and, at the same time, have notably improved their degree of training and education. Nevertheless, women still represent scarcely $20 \%$ of the managers in top teams. It seems that they continue to be held down by an invisible barrier or "glass ceiling" that denies them access to the highest positions in management $[47,48]$. In terms of economic efficiency, organizations in general, and hospitals in particular, are aware that, by restricting the incorporation of women in top management teams, they are losing a high potential value from a part of the population that is very well-prepared, and to which 
valuable resources have been committed in the form of education and professional training [47,48]. Table 2 shows the correlation analysis. The PLS analysis confirms the reliability and unidimensionality of the variables, with general loadings of manifest variables on latent variables exceeding 0.60 . We also assessed for discriminant validity of the measurement model by calculating the average variance extracted (AVE) and comparing this with the squared correlations between constructs. Results showed that discriminant validity was satisfactory because the AVE's were higher than the correlations in all cases.

Table 1. Descriptive statistics for variables $(n=81)$.

\begin{tabular}{lcccc}
\hline \multicolumn{1}{c}{ Variable } & Mean & SD & Theoretical Range & Actual Range \\
\hline 1. Implementation sustainability policies & 2.84 & 0.25 & $0.00-5.00$ & $1.00-5.00$ \\
2. Age diversity & 0.76 & 0.07 & $0.00-1.00$ & $0.74-0.93$ \\
3. Tenure diversity & 0.68 & 0.14 & $0.00-1.00$ & $0.61-0.72$ \\
4. Experience diversity & 0.54 & 0.12 & $0.00-1.00$ & $0.00-1.00$ \\
5. Education diversity & 0.58 & 0.08 & $0.00-1.00$ & $0.00-1.00$ \\
6. Gender diversity & 0.19 & 0.11 & $0.00-1.00$ & $0.00-0.50$ \\
7. TMT heterogeneity & 0.64 & 0.12 & $0.00-1.00$ & $0.00-1.00$ \\
8. Broad-MCS design & 2.98 & 0.27 & $0.00-5.00$ & $1.00-4.00$ \\
9. Short-term Performance & 0.59 & 0.04 & $0.00-1.00$ & $0.42-0.91$ \\
10. Long-term Performance & 0.68 & 0.07 & $0.00-1.00$ & $0.42-0.91$ \\
\hline
\end{tabular}

Table 2. Correlations from PLS model $(n=81)$.

\begin{tabular}{lccccc}
\hline & $\mathbf{1}$ & $\mathbf{2}$ & $\mathbf{3}$ & $\mathbf{4}$ & $\mathbf{5}$ \\
\hline 1. Implementation sustainability policies & $\mathbf{0 . 6 0 8}$ & & & & \\
2. TMT heterogeneity & $0.221^{\mathrm{b}}$ & $\mathbf{0 . 5 5 6}$ & & & \\
3. Broad-MCS design & 0.186 & 0.124 & $\mathbf{0 . 5 7 1}$ & & \\
4. Short-term performance & $-0.218^{\mathrm{b}}$ & $0.203^{\mathrm{b}}$ & 0.159 & $\mathbf{0 . 6 0 2}$ & \\
5. Long-term performance & 0.195 & 0.171 & $0.226^{\mathrm{a}}$ & 0.172 & $\mathbf{0 . 5 9 7}$ \\
\hline Bold-faced elements on the diagonal represent the square root of the Average Variance Extracted (AVE). \\
Off-diagonal elements are Pearson correlations among variables. ${ }^{\text {a }}$ Significant at 0.01 level (two tailed); \\
b Significant at 0.05 level (two tailed).
\end{tabular}

Figure 2 shows the PLS research model we tested. Table 3 contains the detailed output statistics of the path coefficients in the structural model and reports on the significance of the standardized $B_{\mathrm{S}}$ that resulted from this analysis, based on a bootstrapping procedure that used 500 samples with replacement Results in Table 3 show that the implementation of environmental sustainability policies is negatively related to short-term performance, and positively related to long-term performance. Our first hypothesis asserted that TMT diversity moderates the relationship between implementation of environmental sustainability policies and performance, such that effect of such implementation will be more positive in short-term performance than in long-term performance. Table 3 shows support for the moderating effect of TMT diversity on the relationship between the implementation of environmental sustainability policies and short-term performance, since the path coefficient from the interaction term to performance is positive and significant. However, results in Table 3 show that TMT heterogeneity does not moderate the relationship between the implementation of environmental sustainability policies and long-term performance, since the interaction term was positive but non- significant. The control variable size and complexity care did not reveal any significant path with implementation of sustainability policies, TMT heterogeneity, Broad-MCS design or performances. Overall, these results show support for our first hypothesis. 


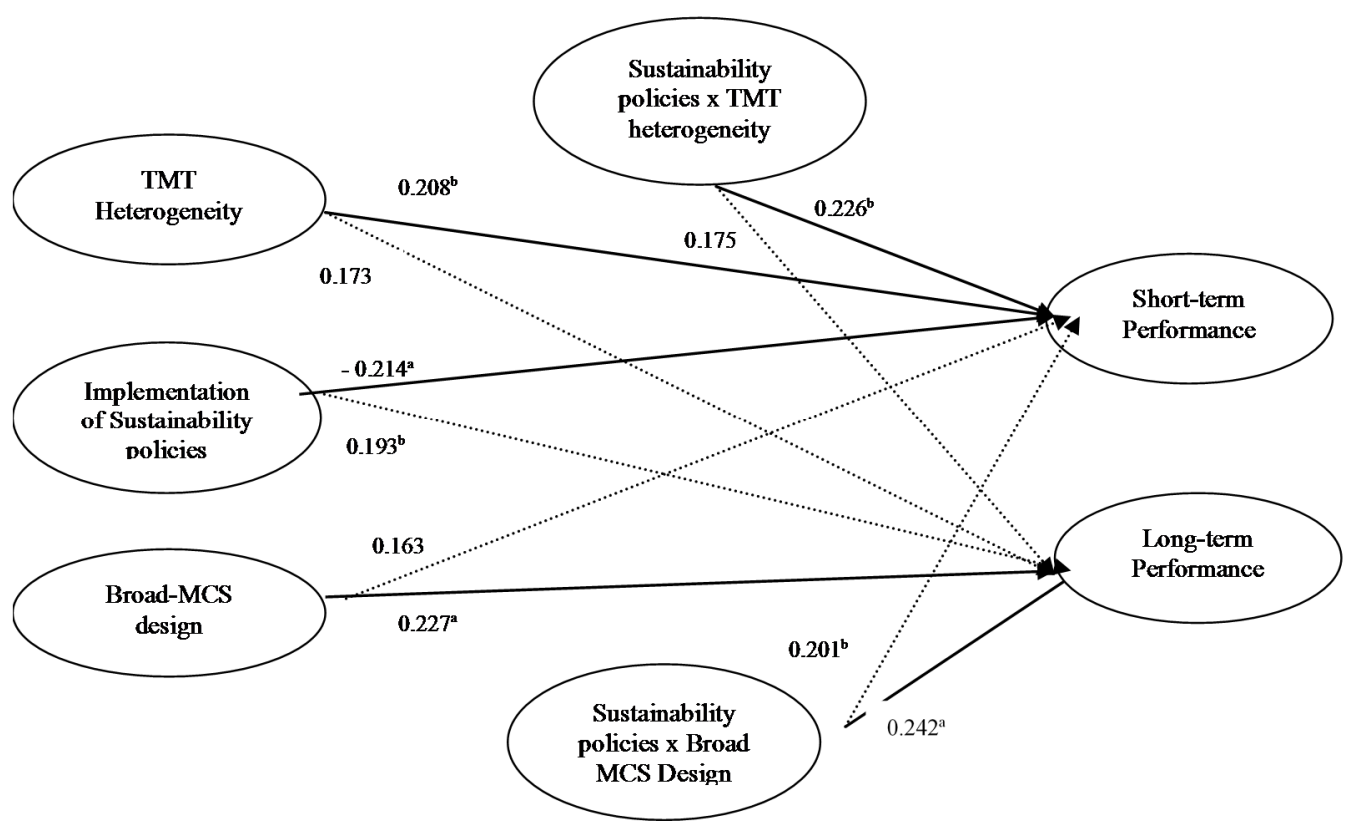

Figure 2. PLS Model.

Table 3. Results from PLS analysis (path coefficients, $n=81$ ).

\begin{tabular}{ccc}
\hline \multicolumn{1}{c}{ To } & $\begin{array}{c}\text { Short-Term } \\
\text { Performance }\end{array}$ & $\begin{array}{c}\text { Long-Term } \\
\text { Performance }\end{array}$ \\
\hline Implementation sustainability policies & $-0.214^{\mathrm{a}}$ & $0.193^{\mathrm{b}}$ \\
TMT heterogeneity & $0.208^{\mathrm{b}}$ & 0.173 \\
Broad-MCS design & 0.163 & $0.227^{\mathrm{a}}$ \\
Sustainability policies $\times$ TMT heterogeneity & $0.226^{\mathrm{a}}$ & $0.175^{\mathrm{a}}$ \\
Sustainability policies $\times$ Broad-MCS design & $0.201^{\mathrm{b}} ; R^{2}=0.279$ & $0.242^{\mathrm{a}} ; R^{2}=0.298$ \\
\hline
\end{tabular}

${ }^{a}$ Significant at 0.01 level (two tailed) ${ }^{b}$ Significant at 0.05 level (two tailed).

Our second hypothesis was about the moderating effect of a broad MCS design in the relationship between the implementation of environmental sustainability policies and both short-term and long-term performance. Table 3 shows support for a moderating effect of broad-MCS design on the relationship between the implementation of environmental sustainability policies and long-term performance, since the path coefficient from the interaction term to long-term performance is positive and significant. The effect of broad-MCS design on the relationship between the implementation of environmental sustainability policies and short-term performance was also positive and significant. Overall, these results show support for a moderating effect of broad-scope MCS design, such that the effect of the implementation of environmental sustainability policies will be more positive in short-term performance than in long-term performance. The explanatory power of the interaction model was calculated through comparison of the $\mathrm{R}^{2}$ for this model with the $\mathrm{R}^{2}$ for the main effects model (without the interaction term). The difference between the squared multiple correlations is used to assess the overall effect size $f^{2}$ for the interaction [45] (p. 211). Results show that the interaction construct has an effect size $f$ of 0.197 , which is between a medium and large effect $\left(f^{2}=\left(R^{2}\right.\right.$ interaction model $-R^{2}$ main model)/ (1- $R^{2}$ main model). Interaction effect sizes are small if $f^{2}=0.02$, medium if $f^{2}=0.15$, and large if $f^{2}=0.35$ [45].).

\section{Discussion and Conclusions}

This paper analyzed the effects of top management team heterogeneity and a broad-scope design of management control systems on the relation between the implementation of environmental 
sustainability policies and both short-term and long-term performance. Our findings showed that a broad-scope design of MCS and TMT heterogeneity moderate the relationship between the implementation of environmental sustainability policies and performance differently. On one hand, TMT heterogeneity helps organizations adopt sustainability strategies to achieve short-term performance. In another hand, a broad-scope design of MCS encourages organizations to adopt sustainability strategies to achieve both long-term performance and short-term performance. This finding is relevant because firms are struggling to find ways to face strategic renewal and adopt environmental sustainability practices successfully. In this line, before setting goals and committing to environmental sustainability policies, health care organizations should examine the diversity of their top management team behind sustainability efforts. Furthermore hospitals and health care organizations should design comprehensive management control systems to guarantee the success of their environmental sustainability programs.

The results of this paper allow us to extend the previous strategy literature and management control literature by explicitly analyzing the role of TMT diversity and broad-scope design of MCS in a fit affecting both short-term performance and long-term performance in firms adopting sustainability strategic policies. Our findings show support for the conclusion that top management teams with diverse characteristics would be better able to handle the conflicting demands of adopting new strategic policies and reducing short-term performance downturn. Regarding the relationships between broad-scope design of MCS and the implementation of sustainability strategies, the findings show that a broad-scope design of MCS facilitates the success of the adoption environmental sustainability policies in the long term and also in the short term. These results are in line with the arguments that broad-scope design of MCS overcomes the lack of relevance of narrow-scope MCS information for managing strategy implementation successfully [13,39].

Given that public healthcare organizations expend more than $15 \%$ of their budget in obtaining and using management information, it is clearly important to study the factors that affect the ways in which these organizations use their MCS effectively, especially in situations where management control systems are critical for implementing environmental sustainability policies in the public interest. We can conclude that TMT heterogeneity and a broad-scope design of MCS are able to prevent firms from adopting environmental sustainability policies and performing worse in the short-term. Furthermore, a broad-scope design of MCS helps organizations implement sustainability strategies to enhance long-term performance. Thus, the results of this study contribute to the literature by addressing the management of strategy implementation without disrupting firm performance [9]. This paper provided evidence that in organizations implementing new strategies, a diverse TMT and a broad-scope design of MCS can help to improve short-term performance and long-term performance, respectively. Thus, we can conclude that organizations adopting environmental sustainability policies should try to ensure that management control systems provide a broad range of information to a diverse TMT, since they are key aspects to thriving in the health care environment of present and future.

This study has also practical consequences, such as the fact that not only does a TMT with diverse characteristics matter for enhancing short-term performance, but also an alignment with a broad design of MCS is necessary to improve long-term performance. Governmental authorities should incentive the adoption of broad-scope MCS to provide a comprehensive range of information to health care managers in hospitals. A TMT with a wide set of skills, training and backgrounds could optimize the effect of strategy implementation on performance. Diverse top management teams could better face the challenge of balances and coordinate patients, financial, organizational and community needs. This may require that authorities responsible for appointing hospital managers pay increased attention to the diversity of characteristics among members of the top team. Diverse backgrounds let managers in the team use typical management information in broader ways than those determined by a single specialization in education and experience. This latter also has implications on the design of contemporary management control systems, which often require diverse expert knowledge on their functional capabilities. This paper also showed the importance of distinguishing 
between long-term and short-term performance, since any successful adoption of environmental sustainability policies should enhance both of them. Future research should focus more closely on identifying other characteristics of TMT, such as cognitive or psychological characteristics, as well as on potential interaction effects between different forms of MCS design.

This paper has several limitations, such as the lack of testing of the directions of causality due to the cross-sectional nature of the questionnaire-based study. Causality cannot be assessed through the use of cross sectional methods like those used in this research. Future research could analyze our research question by using experiments and other research methods that are stronger for demonstrating causality. Furthermore, this paper has focused on a single setting, the Spanish public hospital industry, and thus generalizability of our results should be done with care. Future research could extend our research question to a different industrial setting.

Acknowledgments: This article has benefited from comments from workshop participants at Pablo de Olavide University and Nicolaus Copernicus University. The author would like to acknowledge the partial support from the Andalusia Regional Government (project SEJ-2395) and the Spanish Ministry of Education and Science (project ECO2014-56204P).

Conflicts of Interest: The authors declare no conflict of interest.

\section{Appendix. Questionnaire Items}

Appendix A. Top Management Team Heterogeneity

- Age

- Gender

- University degree and title

- Years of experience as clinician/doctor at public hospitals

- Years of experience as clinician/doctor at other health care organizations

- Years of experience as managers in cur-rent hospital

- Years of experience as managers in other health care organizations

Appendix B. Broad-Scope Design of MCS

Please, indicate the extent of usefulness of the following information elements provided by your management control systems:

- Future-oriented information

- External information

- Non-financial information

- Long-run oriented information

Appendix C. Environmental Sustainability Policies

Please, indicate the extent of adoption in your hospital of the following policies:

- Energy efficient policies

- Policies to reduce wasteful or unnecessary water consumption

- Policies to reduce regulated medical waste generation

- Policies to develop or enhancing recycling programs

- Policies to examine equipment and building systems to determine whether it is operating as designed 


\section{References}

1. Moon, J.; Gond, J.-P.; Grubnic, S.; Herzig, C. Management Control for Sustainability Strategy; Chartered Institute of Management Accountants Research executive summary series: London, UK, 2011.

2. Wagner, M. The role of corporate sustainability performance for economic performance: A firm-level analysis of moderation effects. Ecol. Econ. 2010, 69, 1553-1560. [CrossRef]

3. HPOE. Environmental Sustainability in Hospitals: The Value of Efficiency; Health Research \& Educational Trust: Chicago, IL, USA, 2014.

4. Carnero, M.C. Assessment of environmental sustainability in health care organizations. Sustainability 2015, 7, 8270-8291. [CrossRef]

5. Grose, J.; Bennallick, M.; Nichols, A.; Pahl, S.; Richardson, J. Facilitating Sustainable Waste Management Behaviors Within the Health Sector: A Case Study of the National Health Service (NHS) in Southwest England, UK. Sustainability 2012, 4, 630-642. [CrossRef]

6. Fischer, M. Fit for the future? A new approach in the debate about what makes healthcare systems really sustainable. Sustainablity 2015, 7, 294-312. [CrossRef]

7. Casto, M.F.; Mateus, R.; Serôdio, F.; Bragança, L. Development of Benchmarks for Operating Costs and Resources Consumption to be Used in Healthcare Building Sustainability Assessment Methods. Sustanaibility 2015, 7, 13222-13248. [CrossRef]

8. Ye, J.; Marinova, D.; Singh, J. Strategic change implementation and performance loss in the front lines. J. Mark. 2007, 71, 156-171. [CrossRef]

9. Kaplan, R.S.; Norton, D.P. How to Implement a New Strategy without Disrupting Your Organization. Harv. Bus. Rev. 2006, 3, 100-109. [CrossRef]

10. Al-Ansaari, Y.; Chen, C. Strategic orientation and business performance: An empirical study in the UAE context. Manag. Decis. 2015, 53, 2287-2302. [CrossRef]

11. Osborne, S.; Brown, K. Managing Change and Innovation in Public Service Organisations; Routledge: London, UK, 2005.

12. Mintzberg, H.; Ahlstrand, B.; Lampel, J. Strategy Safari; Simon \& Schuster: London, UK, 2005.

13. Langfield-Smith, K. Strategic management accounting: How far have we come in 25 years? Account. Audit. Account. J. 2008, 21, 204-228.

14. Marginson, D. Management controls systems and their effects on strategy formation at middle-management levels: Evidence from a U.K. organization. Strateg. Manag. J. 2002, 23, 1019-1031. [CrossRef]

15. Pondeville, S.; Swaen, V.; De Rongé, Y. Environmental management control systems: The role of contextual and strategic factors. Manag. Account. Res. 2013, 24, 317-332. [CrossRef]

16. Finkelstein, S.; Hambrick, D.C.; Cannella, A. Strategic Leadership: Theory and Research on Executives, Top Management Teams, and Boards; University Press: Oxford, UK, 2009.

17. Hambrick, D.C. Upper echelons theory: An update. Acad. Manag. Rev. 2007, 32, 334-343. [CrossRef]

18. Cho, T.S.; Hambrick, D.C. Attention as the mediator between top management team characteristics and strategic change: The case of airline deregulation. Org. Sci. 2006, 17, 453-469. [CrossRef]

19. Goll, I.; Johnson, N.; Rasheed, A. Top management team demographic characteristics, business strategy, and firm performance in the US airline industry: The role of managerial discretion. Manag. Decis. 2008, 46, 201-222. [CrossRef]

20. Ruiz-Iglesias, L. Claves Para la Gestión Clínica; McGraw Hill: Madrid, Spain, 2004.

21. Yang, L.; Wang, D. The impacts of top management team characteristics on entrepreneurial strategic orientation: The moderating effects of industrial environment and corporate ownership. Manag. Decis. 2014, 52, 378-409. [CrossRef]

22. Thomas, A.; Ramaswamy, K. Matching Managers to Strategy: Further Tests of the Miles and Snow Typology. Br. J. Manag. 1996, 7, 247-261. [CrossRef]

23. Cuganesan, S.; Dunford, R.; Palmer, I. Strategic management accounting and strategic practices within a public sector agency. Manag. Account. Res. 2012, 23, 245-260. [CrossRef]

24. Carpenter, M.A.; Geletkanycz, M.A.; Sanders, W.G. Upper Echelons Research Revisited: Antecedents, Elements, and Consequences of Top Management Team Composition. J. Manag. 2004, 30, 749-778.

25. Bell, S.T.; Villado, A.J.; Lukasik, M.A.; Belau, L.; Briggs, A.L. Getting specific about demographic diversity variable and team performance relationships: A meta-analysis. J. Manag. 2011, 37, 709-743. [CrossRef] 
26. Kauer, D.; Prinzessin zu Waldeck, T.; Schäffer, U. Effects of top management team characteristics on strategic decision making: Shifting attention to team member personalities and mediating processes. Manag. Decis. 2007, 45, 942-967. [CrossRef]

27. Hentschel, T.; Shemla, M.; Wegge, J.; Kearney, E. Perceived diversity and team functioning: The role of diversity beliefs and affect. Small Group Res. 2013, 44, 33-61. [CrossRef]

28. Nielsen, B.B.; Nielsen, S. Top management team nationality diversity and firm performance: A multilevel study. Strateg. Manag. J. 2013, 34, 373-382. [CrossRef]

29. Hiebl, M. Upper echelons theory in management accounting and control research. J. Manag. Control 2014, 34, 223-240. [CrossRef]

30. Santos, V.; García, T. The Complexity of the organizational renewal decision: The management role. Leadersh. Organ. Dev. J. 2006, 28, 336-355. [CrossRef]

31. Trinh, H.Q.; O'Connor, S.J. Helpful or Harmful? The Impact of Strategic Change on the Performance of U.S. Urban Hospitals. Health Serv. Res. 2002, 37, 143-169.

32. Naranjo-Gil, D.; Hartmann, F.; Maas, V. Top management team heterogeneity, strategic change and operational performance. Br. J. Manag. 2008, 19, 222-234. [CrossRef]

33. Hambrick, D.C.; Cho, T.S.; Chen, M. The influence of top management heterogeneity on firms' competitive moves. Adm. Sci. Q. 1996, 41, 659-684. [CrossRef]

34. Chatman, J.A.; Flynn, F.J. The influence of demographic heterogeneity on the emergence and consequences of cooperative norms in work teams. Acad. Manag. J. 2001, 44, 956-974. [CrossRef]

35. Naranjo-Gil, D.; Hartmann, F. How top management teams use management accounting systems to implement strategy. J. Manag. Account. Res. 2006, 18, 21-53. [CrossRef]

36. Chenhall, R. Accounting for the horizontal organization: A review essay. Account. Org. Soc. 2008, 33, 517-550. [CrossRef]

37. Cadez, S.; Guilding, C. An exploratory investigation of an integrated contingency model of strategic management accounting. Account. Org. Soc. 2008, 33, 836-863. [CrossRef]

38. Bouwens, J.; Abernethy, M.A. The consequences of customization on management accounting systems design. Account. Org. Soc. 2000, 25, 221-259. [CrossRef]

39. Chenhall, R. Management control systems design within its organizational context: Findings from contingency-based research and directions for the future. Account. Org. Soc. 2003, 28, 127-168. [CrossRef]

40. Martello, M.; Watson, J.G.; Fischer, M.J. Implementing a balanced scorecard in a not-for-profit organization. J. Bus. Econ. Res. 2008, 6, 67-80. [CrossRef]

41. Ho, J.; $\mathrm{Wu}, \mathrm{A} . ; \mathrm{Wu}, \mathrm{S}$. Performance measures, consensus on strategy implementation, and performance: Evidence from the operational-level of organizations. Account. Org. Soc. 2014, 29, 38-58. [CrossRef]

42. Dillman, D.A. Mail and Internet Surveys: The Tailored Design Method; John Wiley and Sons: New York, NY, USA, 2000.

43. Van Peursem, K.A.; Pratt, M.J.; Lawrence, S.R. Health management performance: A review of measures and indicators. Account. Audit. Account. J. 1995, 8, 34-70. [CrossRef]

44. Jonge, P.; Huyse, F.J.; Slaets, J.P.; Herzog, T.; Lobo, A.; Lyons, J.S.; Opmeer, B.C.; Stein, B.; Arolt, V.; Balogh, N.; et al. Care complexity in the General Hospital: Results from a European Study. Psychosomatics 2001, 42, 204-212. [CrossRef] [PubMed]

45. Chin, W.W.; Marcolin, B.L.; Newsted, P.R. A partial least squares latent variable modeling approach for measuring interaction effects: Results from a Monte Carlo simulation study and voice mail emotion/adoption study. Inf. Syst. Res. 2003, 14, 189-217. [CrossRef]

46. Wetzels, M.; Odekerken-Schroder, G.; van Oppen, C. Using PLS Path Modeling for Assessing Hierarchical Construct Models: Guidelines and Empirical Illustration. MIS Q. 2009, 33, 177-195.

47. Krishnan, H.A.; Park, D. A few good women-on top management teams. J. Bus. Res. 2005, 58, $1712-1720$. [CrossRef]

48. UN Women Annual Report 2014-2015; The United Nations: New York, NY, USA, 2015.

(C) 2016 by the author; licensee MDPI, Basel, Switzerland. This article is an open access article distributed under the terms and conditions of the Creative Commons Attribution (CC-BY) license (http:/ / creativecommons.org/licenses/by/4.0/). 